\title{
Modern Vector Control
}

\author{
Neil F. Lobo, Nicole L. Achee, John Greico, and Frank H. Collins \\ Department of Biological Sciences, University of Notre Dame, Notre Dame, Indiana 46556 \\ Correspondence: frank@nd.edu
}

\begin{abstract}
The rapid spread of mosquito resistance to currently available insecticides, and the current lack of an efficacious malaria vaccine are among many challenges that affect large-scale efforts for malaria control. As goals of malaria elimination and eradication are put forth, new vector-control paradigms and tools and/or further optimization of current vector-control products are required to meet public health demands. Vector control remains the most effective measure to prevent malaria transmission and present gains against malaria mortality and morbidity may be maintained as long as vector-intervention strategies are sustained and adapted to underlying vector-related transmission dynamics. The following provides a brief overview of vector-control strategies and tools either in use or under development and evaluation that are intended to exploit key entomological parameters toward driving down transmission.
\end{abstract}

\begin{abstract}
M alaria, dengue, and other mosquito-borne diseases are public health problems in many parts of the world. There were an estimated 214 million cases and 438,000 deaths attributed to malaria in 2015 (WHO 2015a). Malaria-control strategies that have shown success include treatment of infected individuals with drugs, application of insecticide to reduce mosquito populations through indoor residual spray (IRS), and reduction of human contact with infected mosquitoes via insecticide-treated nets (ITNs) (D'Acremont et al. 2010; O'Meara et al. 2010). In 5 years (between 2000 and 2015), the global incidence of malaria fell $37 \%$ and malaria mortality decreased by $60 \%$ (WHO 2015a). However, $\sim 3.2$ billion people remain at risk of malaria, with continued associated morbidity and mortality.

Vector control remains the most effective measure to prevent malaria transmission.
\end{abstract}

Vector-targeted interventions have been successful at reducing malaria mortality and morbidity worldwide-both historically and presently (WHO 2015a). The core goal of vector control is to reduce the vectorial capacity of a vector population below that required to maintain a malaria reproduction rate $\left(R_{0}\right)$ of greater than 1 - where $R_{0}$ is the number of human malaria cases that result from each human case in a population (malERA Consultative Group on Vector Control 2011). This has been shown from larval control in Brazil (Soper and Wilson 1943) and Egypt (Shousha 1948) in the 1940s, to the discovery of dichloro-diphenyl-trichloroethane (DDT) for use in IRS campaigns and present-day long-lasting insecticide-treated nets (LLINs). Vector control hence remains an integral part of the Global Malaria Control Strategy (GMSC) (WHO 1993). These remarkable effects and value to global health should be

Editors: Dyann F. Wirth and Pedro L. Alonso

Additional Perspectives on Malaria: Biology in the Era of Eradication available at www.perspectivesinmedicine.org

Copyright (C) 2018 Cold Spring Harbor Laboratory Press; all rights reserved; doi: 10.1101/cshperspect.a025643

Cite this article as Cold Spring Harb Perspect Med 2018;8:a025643 
N.F. Lobo et al.

maintained as long as vector-related interventions are sustained and remain viable.

Effective vector control depends on the overlap between the specific intervention and susceptible vector behaviors (Elliott 1972; Bayoh et al. 2010; malERA Consultative Group on Vector Control 2011; Kiware et al. 2012; Killeen et al. 2013, 2014; Russell et al. 2013; Killeen 2014). Essentially, an intervention is more efficient if it functions on repeated vector behaviors such as ITNs killing susceptible mosquitoes when they look for a blood meal, which occurs once during a gonotrophic cycle and subsequently several times during the mosquito's life span (Killeen et al. 2014). Treated nets are, therefore, most efficient if the vector population hostseeks indoors while the local human population is asleep. In a similar manner, IRS is most effective against indoor resting vectors (Killeen et al. 2014). However, malaria transmission can be maintained by many vector species despite high coverage of ITNs and/or IRS as they may show behaviors that allow them to escape the effect of these interventions (Bugoro et al. 2011; Russell et al. 2013; Bayoh et al. 2014; Killeen 2014). With the case of ITNs, vector populations may avoid the intervention by feeding outside or early in the evening - at times when people are not sleeping under nets (Russell et al. 2013). Insecticide resistance will also impact the lethal effects of these interventions (Toe et al. 2014; Glunt et al. 2015).

Gains achieved by vector control in reducing malaria transmission cannot be relaxed without the expectation of a rebound in malaria incidence. Both a historical review and simulation modeling suggest that a scale-back of malaria vector control has a high probability of malaria resurgence for most scenarios, even where malaria transmission is very low or has been interrupted (WHO 2015b). In addition, residual transmission, that is, malaria transmission that happens outside the limits of the interventions in use (such as early-evening or outdoor biting in which ITNs are primary strategy) (Killeen 2014; WHO 2014), and insecticide resistance to pyrethroids - the most commonly used synthetic chemicals (Quinones et al. 2015; World Health Organization pesticide evaluation scheme [WHOPES], www.who.int/whopes/ en), remain the biggest threats to control and elimination strategies. Indeed, studies suggest that current interventions strategies that rely primarily on ITNs and IRS are insufficient to eliminate or eradicate malaria (Shaukat et al. 2010) and a shift to the use of nonpyrethroids in Africa has occurred (N'Guessan et al. 2007; Mnzava et al. 2015). These points are the impetus for several novel intervention strategies being evaluated or developed. Such new tools are targeting transmission dynamics, vector species, and behaviors not susceptible to present interventions to include outdoor transmission, animal biting, sugar feeding, and the immature stage of the vector.

\section{CORE WORLD HEALTH ORGANIZATION VECTOR-CONTROL STRATEGIES}

Both ITNs and IRS remain core malaria-intervention strategies worldwide. These WHOrecommended interventions combined with chemoprevention in pregnant women and children, diagnostic testing, and access to treatment have largely contributed to the gains against malaria in the last few years (WHO 2015a). Typically, used independently, studies to determine impact from combination use have been conducted to help guide further gains. In Mozambique and Equatorial Guinea, protective effects of IRS with ITNs have been suggested to be additive (Kleinschmidt et al. 2009; Hamel et al. 2011; Fullman et al. 2013; West et al. 2014, 2015). Other studies found no evidence of an added benefit when combining ITS and ITNs (Nyarango et al. 2006; Corbel et al. 2012; Pinder et al. 2015; Protopopoff et al. 2015), whereas others remain unclear (Gimnig et al. 2016), pointing to the requirement of additional evidence (WHO 1993).

\section{Insecticide-Treated Nets (ITNs)}

ITNs, a form of personal protection, function by both providing a physical barrier to mosquitoes as well as the lethal effect of insecticides that are present on the bednet material. With high coverage, the size as well as the life span of the vector 
population is reduced-further protecting the community (Hawley et al. 2003). This intervention targets a permethrin (or insecticide-in-use) susceptible vector population that host-seeks indoors, whereas the local human population is asleep under a treated net and functions once per gonotrophic cycle. ITNs are consequently most effective against late-night and indoor-biting vectors. Historically, mosquito nets have been used against nuisance insects (Lindsay and Gibson 1988; Lengeler 2004). Studies in the 1980s showed that pyrethroids were safe for humans and both repelled and killed mosquitoes-showing that ITNs resulted in both individual and community-wide protection against malaria infection (Lengeler 2000, 2004). Driven by increasing access and distribution of ITNs, the proportion of the population sleeping under an ITN has increased dramatically in sub-Saharan Africa since 2000. However, the increasing number of ITNs have been insufficient to achieve universal coverage (WHO 2015a) and, this, along with the increasing spread of insecticide resistance (N'Guessan et al. 2007; Temu et al. 2012; Mulamba et al. 2014; Toe et al. 2014; Mnzava et al. 2015) and behavioral modification by the vector (Bayoh et al. 2010; Russell et al. 2013; Glunt et al. 2015), may point to the limits of the effectiveness of this intervention (Bayoh et al. 2014; WHO 2015a).

\section{Indoor Residual Spraying (IRS)}

IRS is the application of insecticide to the inside of human habitation, that is, walls and other surfaces that may serve as a resting place for malaria vectors. IRS effects result in knockdown and/or mortality of those vector populations that rest on these treated surfaces and are susceptible to the insecticide in use. IRS generally functions once per gonotrophic cycle when a mosquito rests on the sprayed surface before or after a blood meal. Historically, IRS with DDT has reduced malaria in many settings around the world. IRS contributed to the elimination of malaria from parts of Asia, Russia, Europe, and Latin America. Successful IRS programs were the primary mosquito intervention during the Global Malaria Eradication Campaign
(1955-1969) and have contributed to the elimination of malaria from parts of Asia, Russia, Europe, and Latin America, with successful IRS programs showed in parts of Africa. The successful use of IRS in Mozambique, South Africa, Swaziland, and Zimbabwe (Mabaso et al. 2004) prompted its present reintroduction as a primary tool in vector-control strategies with a shift to nonpyrethroids (N'Guessan et al. 2007; Mnzava et al. 2015) due to the increase in insecticide resistance of malaria vectors across Africa. Although IRS coverage has declined (primarily due to the cost of insecticides) in recent years, 2014 represents the largest proportion of the population being protected by IRS in Africa (WHO 2015a). Annual rotation of IRS insecticides is currently the best practice for resistance management in malaria vectors in most settings (Mnzava et al. 2015).

Both IRS and ITNs are effective tools for reducing disease. Studies in Mozambique and Equatorial Guinea have indicated that protective effects of IRS with ITNs may be (West et al. 2014, 2015) additive (Kleinschmidt et al. 2009; Hamel et al. 2011; Fullman et al. 2013). Other studies found no evidence of an added benefit when combining ITS and ITNs (Nyarango et al. 2006; Corbel et al. 2012; Pinder et al. 2015; Protopopoff et al. 2015), whereas others remained unclear (Gimnig et al. 2016), pointing to the requirement of additional evidence (WHO 1993).

\section{Larval Source Management}

Larval source management (LSM) is the management of bodies of water-potential larval habitats for mosquitoes, in an effort to prevent the completion of development of the immature stages (Tusting et al. 2013). Unlike IRS and LLINs, which target the adult stages, LSM targets the immature larval and pupal stages in the attempt to reduce the number of adult mosquitoes. LSM functions once in the lifetime of a mosquito during its larval stage. The four types of LSM-all directed toward limiting the adult population-include habitat modification, habitat manipulation, chemical larviciding, and biological control. 
N.F. Lobo et al.

Habitat or environmental modification is meant to be permanent and includes drainage, filling, land leveling, and alteration of water reservoirs. Essentially, naturally occurring pools, pockets, and seepage ponds — suitable habitats for immature mosquitoes-are modified by the reinforcement of banks, deepening of channels, or diversion of flow (WHO 2013). Filling of holes, pits, and ponds in and around human habitation is a more simple method of habitat modification but requires more frequent management (WHO 2013). Habitat manipulation, on the other hand, is a recurrent activity more associated with agriculture, such as in rice cultivation (Mabaso et al. 2004; Temu et al. 2012). The manipulation temporarily reduces or removes mosquito habitat or kills immature stages. This includes changing the salinity of breeding sites (desalination or salination), flushing of streams and water bodies, regulation of the water level in reservoirs, as well as removal of vegetation for increased exposure to sunlight (WHO 2013). Larviciding is the regular application of insecticides, whether synthetic or natural, to water bodies (WHO 2013). These include a wide range of emulsifiable concentrates, suspension concentrates, water-dispersible granules, wettable powders, granules, pellets, and briquettes (WHO 2013). Bacterial, or biological, larvicides are highly effective with the added benefit of being selective, and having minimal nontarget effects. Bacillus thuringiensis subsp. israelensis (Bti) and Bacillus sphaericus (Bs) are the primary biologicals used for malaria vector control (WHO 2013). These bacteria produce a highly specific endotoxin, affecting only larvae of mosquitoes, black flies, and midges and are effective where target organisms are resistant to other larvicides (Fillinger et al. 2003; WHO 2013). Spinosad, another bacterial larvicide, is a combination of metabolites from the bacterium Saccharopolyspora spinosa. Insect growth regulators such as methoprene and pyriproxyfen, mimic mosquito juvenile hormone and prevent the development of larvae to the pupal stage subsequently killing the vector. Globally, trends indicate an increased use of insect growth regulators for the control of malaria vectors; however, this is minimal relative to oth- er methods of vector control (WHOPES). Biological control is the introduction of natural aquatic predators into the breeding habitat (WHO 2013). These include fungi (e.g., Laegenidium giganteum) and mermithid nematodes (e.g., Romanomermis culicivorax), which parasitize and kill larval mosquitoes; however, these are not widely used because of inefficiency. Likewise, mosquito-eating fish (such as Gambusia affinis and Poecilia reticulate) have largely been ineffective except in a few studies. A recent Cochrane review (Tusting et al. 2013; Walshe et al. 2013) on the use of larvivorous fish as a malaria intervention concluded that there is a lack of evidence and insufficient research to show whether larvivorous fish consistently reduce the density of malaria vectors and malaria.

LSM has a long history of use in diverse settings with various levels of success in urban, lowtransmission and elimination settings (Watson 1911, 1953; Hopkins 1940; Soper and Wilson 1943; Muirhead-Thomson 1945, 1951; Shousha 1948; Holstein 1954; Clyde 1967; Fillinger et al. 2009; Fillinger and Lindsay 2011). Its contributions to recent successes in reductions of malaria burden have not been considered substantial although there has been a significant amount of attention. A 2012 review by the WHO Malaria Policy Advisory Committee (WHO 2012b) combined with a 2013 Cochrane review on mosquito LSM for controlling malaria (Tusting et al. 2013), determined that larviciding should only have a limited role in malaria control in areas where mosquito breeding sites are few, fixed, and findable (Tusting et al. 2013; WHO 2012b). An additional term "fixable" (T Burkot, pers. comm.) has also been proposed to be required, with the concern that these may not be "fixable" with LSM (e.g., large lagoon breeding sites of Anopheles farauti in the Solomon Islands) (Bugoro 2011). An additional Cochrane review on larvivorous fish for preventing malaria transmission (Walshe et al. 2013) found no reliable studies that report that the introduction of larvivorous fish has an effect on malaria infection in nearby communities, on entomological inoculation rate, or on adult anopheline density.

A WHO operational manual (WHO 2013) provides guidance on the planning, implemen- 
tation, management, and evaluation of LSM strategies. The combination of a lack of scientific studies showing effect as well as the need for better understanding of basic larval biologyhabitats, abundance, behavior, and distribution of the larvae of malaria vectors (Fillinger et al. 2004) agree with the WHO emphasis that LSM programs need to be tailored to local environmental conditions and should be based on comprehensive and cost-effectiveness studies-that is, require evidence based decision making. LSM requires a comprehensive infrastructure composed of trained individuals, a monitoring system with appropriate logistical and analysis capabilities and a timely feedback and reaction system, with financial, community, and political commitment.

The success of LSM on malaria control depends, in part, on the basic reproductive number for malaria, $R_{0}$ and the EIR capacity (Garrett-Jones and Shidrawi 1969; Killeen et al. 2000; Smith et al. 2007). LSM, with the effect being on the larval and pupal stages, has a linear and not exponential effect on $R_{0}$ and is only as effective as its implementation. These interventions are affected by the heterogeneous distribution of adult emergence rates from larval habitats. If the removal of a few larval breeding sites drastically reduced adult mosquitoes populations, LSM may possibly produce a large effect on malaria transmission with little effort (Smith et al. 2007; WHO 2012b). Biological control may have a large impact in the steady state balance of an introduced insect but not necessarily on a naturally present vector.

\section{Host-Mediated Control Zooprophylaxis}

In malaria endemic settings where transmission is in part the result of zoophilic vectors, two routes of control have been suggested: diversion of vectors away from human hosts to alternative nonhuman blood meal sources (zooprophylaxis) and the use of nonhuman hosts as bait to attract vectors to a toxic host or blood meal source (insecticide-treated livestock/endectocides). This intervention targets a vector population that prefers feeding on animals and func- tions once per gonotrophic cycle. The effect this intervention has on the vector population is directly proportional to the amount of zoophagy present.

Zooprophylaxis is considered to be controversial in its potential for both beneficial and detrimental outcomes. For example, despite diverting vectors to nonhuman host sources, the use of livestock may actually result in zoopotentiation (Saul 2003), suggesting that the larger numbers of animals and the ease of acquiring a blood meal could result in less time spent hostseeking. This would thereby correspond to reduced vector mortality overall and a potential increase in the number of blood meals taken on humans by infectious vectors. In situations where livestock are kept in close proximity to humans, animals may actually increase the risk of mosquito bites to individual persons by attracting vectors to the general proximity of human hosts (Schultz 1989; Hewitt et al. 1994; Bouma and Rowland 1995). Despite these scenarios, the use of insecticide-treated livestock and endectocides is gaining in popularity (Donnelly et al. 2015; Chaccour and Killeen 2016).

The expectation is that zooprophylaxis would have the greatest impact on malaria transmitted as a result of zoophilic vectors. The efficacy of zooprophylaxis may be enhanced by attracting vectors to insecticide-treated livestock. This approach has been attempted in both the United States (Nasci et al. 1990) and the Philippines (delas Llagas et al. 1996). Treatment of all domesticated animals with insecticides resulted in a decrease of malaria incidence and prevalence in Pakistan (Hewitt et al. 1994). Although there have been encouraging findings, the impact of insecticide-treated livestock on malaria transmission in Africa has yet to be assessed.

\section{Endectocides}

Endectocides are classified as systemic drugs with both endoparasitocidal and ectoparasitocidal activity (Foy et al. 2011). Drugs used against endoparasites such as Avermectin and Ivermectin have long been known to have a killing effect on a number of blood-sucking arthropods. Endectocides hold several advantages 
N.F. Lobo et al.

over traditional insecticides-these interventions travel with the host and do not rely on time or place to be effective. The primary advantage is that this strategy will be effective against endophagic, exophagic, and zoophilic vectors as well as crepuscular and night-biting vectors (Foy et al. 2011). In addition, the mode of action for endectocides ensures that there is a low probability of cross-resistance with current insecticidal strategies (Strycharz et al. 2008). This increases their usage where pyrethroidbased interventions are threatened by insecticide resistance. Last, these systemic drugs have the potential to inhibit the development of the malaria parasite, thus making them a viable target to combat drug resistance in the malaria parasite. Although endectocide use is an attractive option for malaria control, issues of cost (Burnham and Mebrahtu 2004; Goldman et al. 2007), long-term human use (Duke et al. 1990; Guzzo et al. 2002), and resistance buildup in both endo- and ectoparasites (Bourguinat et al. 2007) have been raised. Alternatives to this approach are to use treated livestock as the delivery medium for the endectocide to host-seeking vectors. Such approaches would again be focused on zoophagic vectors but would reduce health impacts associated with maintaining human populations on long-term drug therapy.

Focusing solely on these drugs ability to reduce vector abundance in intervention programs may be too simplistic (Wilson 1993), and these strategies need to be assessed for their ability to affect all variables associated with vectorial capacity.

\section{Push-Pull Strategies}

Personal protective measures have shown usage for preventing malaria (Hill et al. 2007, 2014; Syafruddin et al. 2014) and for reducing the overall intensity of outdoor biting (Goodyer et al. 2010). Using interventions focused on repelling mosquitoes from an individual, however, have prompted concerns that diverted vectors may result in higher attack rates on unprotected populations (Maia et al. 2013). Therefore, a strategy that relies on killing mos- quitoes and reducing community-level risk is much more desirable (Howard et al. 2000).

One novel strategy currently being developed uses a push-pull approach that seeks to exploit the complementary effects of repellents and traps. Developed initially as a way to control agricultural and urban pests (Cook et al. 2007), push-pull interventions work by combining the repellency action of one component and the attractiveness of another to elicit movement away from a protected resource and toward a trap for subsequent removal from the environment (Pyke et al. 1987; Cook et al. 2007; Kitau et al. 2010; Reddy and Guerrero 2010; Paz-Soldan et al. 2011; Menger et al. 2014; Wagman et al. 2015). Accordingly, push-pull strategies for the control of mosquito vectors of human disease would use repellents to deter host-seeking mosquitoes from treated spaces toward a baited trap resulting in their capture and removal from the peridomestic environment thereby decreasing population densities for added community protection and/or personal protection of hosts in the outdoor environment (Cook et al. 2007; Kitau et al. 2010; Paz-Soldan et al. 2011). Although still in the proof-of-concept phase, preliminary studies have been encouraging (Kitau et al. 2010; Menger et al. 2014; Wagman et al. 2015), showing reduced biting rates and house entry.

\section{Spatial Repellents}

The term spatial repellent is used here as a general term to refer to chemical products designed to release volatile chemicals into the air and elicit a range of insect behaviors induced by airborne chemicals that result in a reduction in human-vector contact (Achee et al. 2012a; WHO 2012a). A large number of products are commercially available that use chemical actives registered as spatial repellents (U.S. Environmental Protection Agency [EPA]). These products range in cost and sophistication from expensive heat driven electrical outlet plugins used in the Europe to inexpensive mosquito coils that are widely used throughout Africa and Asia.

Spatial repellents can induce mosquitoes to move away from a chemical stimulus, interfere 
with their host detection (attraction-inhibition) and/or feeding response (WHO 2012a) and consequently can operate on all adult behaviors that incorporate movement. These effects have been measured in laboratory studies (Grieco et al. 2005; Suwannachote et al. 2009), in phase II testing under experimentally controlled conditions (Grieco et al. 2000, 2007; Ogoma et al. 2012), and in field settings (Pates et al. 2002; Kawada et al. 2004a,b; Lucas et al. 2007) against Aedes spp., Anopheles spp., and Culex spp. of varying insecticide resistance profiles. There is also evidence from a phase III study in Indonesia that spatial repellents can impact malaria incidence (Syafruddin et al. 2014).

The role for spatial repellents in modern vector control can best be conceptualized for transmission settings in which IRS and/or LLINs may not offer full protection or have reached their efficacy limits, especially in areas with residual transmission or areas where elimination is proposed. Control of malaria in these areas will require new approaches and this may be where spatial repellency would be most effective (Achee et al. 2012b; Ogoma et al. 2012, 2014). Spatial repellents may show effect against insecticide-resistant populations and have the potential to limit the spread of insecticide-resistant alleles because of reduced selection pressure when considering the nonlethality of effect (WHO 2012a). Spatial repellents could be offered as stand-alone tools where no other interventions are currently in use; or, most likely, combined with existing interventions to augment efficacy of these other tools.

\section{Attractive Toxic Sugar Baits}

Attractive toxic sugar baits (ATSBs) represent a new tool for the indoor and outdoor control of mosquito disease vectors. Mosquitoes are killed when they are attracted to and feed on toxic sugar meals that are either sprayed on plants or used in bait stations. This intervention targets a toxin susceptible vector population while sugar feeding. Because sugar feeding has been shown to occur repeatedly and often in the adult mosquito, the potential effects of this intervention on a vector population may be dramatic.
The use of sugar feeding to reduce mosquito populations was first reported in 1965 (Lea 1965) and then in several other studies (Schlein and Pener 1990; Robert et al. 1997; Muller and Schlein 2006; Xue et al. 2006; Schlein and Muller 2008; Muller et al. 2010b,c) in Aedes and other Culicine mosquitoes as well as sand flies. Effects on anopheline populations were shown in Israel and Mali (Muller et al. 2008, 2010b). This approach may be used in either of two ways, that is, direct mortality induced by feeding on the bait, and/or, the bait may be used to disseminate mosquito pathogens or toxins (Schlein and Pener 1990; Allan 2011).

Attractive toxic sugar bait solutions are composed of sugar, an attractant such as a flower scent, and an oral toxin. Toxins tested include malathion (Lea 1965), boric acid (Xue and Barnard 2003), spinosad (Muller and Schlein 2006), fipronil (Xue et al. 2008), as well as several other classes of insecticide (Muller and Schlein 2006). Toxins, such as boric acid, hold the added advantage of being safe for the environment. Attractants focus on locally acquired sugars, juices and fruit-as mosquitoes may be selective to carbohydrate choices originating from their geographic range (Grimstad and DeFoliart 1974; Muller and Schlein 2005; Muller et al. 2010a).

Sugars derived from plants are an integral component of mosquito nutrition and provide energy for survival, flight, and enhance fecundity and vectorial capacity (Nayar and Sauerman 1971, 1975a,b; Foster 1995; Briegel 2003; Gu et al. 2011). Both male and female mosquitoes may feed on sugar sources several times a day-primarily after emergence and then as required (Reisen et al. 1986; Foster 1995; Foster and Takken 2004; Gary and Foster 2006). Because sugar feeding occurs more often than blood feeding and continues throughout the life of the insect, this behavior represents an opportunity in a mosquito life cycle where a vector intervention may be placed. An accumulative effect of ATSBs on a mosquito population was shown for an area with readily available alternate sugar sources; however, the overall population level lethality was delayed relative to sugar poor areas (Beier et al. 2012). This sug- 
N.F. Lobo et al.

gests that ATSBs may be highly effective in arid, sugar-poor environments.

The recurrent nature of sugar feeding suggests a large ATSB effect on vectorial capacity (Garrett-Jones and Shidrawi 1969; Gu et al. 2011). A single application of ATSBs affected mosquito density, parity, survival, and hence vectorial capacity (Garrett-Jones and Shidrawi 1969; Beier et al. 2012). ATSBs in conjunction with other interventions like bednets might show an exponential effect as energy-deprived mosquitoes (e.g., those that are unable to acquire a blood meal because of bednets) seem to take more and larger sugar meals (Stone et al. 2012). A primary drawback of this strategy is the possibly effect on nontarget organismsthe killing of other sugar feeding insects (honey bees and pollinators in particular).

Although ATSB approaches are being developed and tested, they represent new powerful tools for the control of malaria vectors, especially because this method is simple, inexpensive, and environmentally friendly, and has been shown to be highly effective for mosquito control.

\section{Genetic Control}

Genetic control of malaria vector populations can be described as the dissemination of genetic or inheritable factors toward the decrease of disease and/or target vector populations. These control strategies rely on the dispersal of a modified organism for the purpose of mating with wild-type populations and are therefore species-specific. These strategies are expected to function synergistically with current and other proposed disease-intervention programs.

Curtis first presented the concept of genetic control in 1968 (Curtis 1968). Recent advances in molecular biology have resulted in the germline transformation of several anopheline species (Catteruccia et al. 2000; Grossman et al. 2001; Perera et al. 2002; Lobo et al. 2006). These systems have shown a reduction in vector competence (James et al. 1999; de Lara Capurro et al. 2000; Ito et al. 2002; Bian et al. 2013; Wilke and Marrelli 2015) and have further progressed to developing drivers that can disseminate these systems into natural populations (Burt 2003; Deredec et al. 2008; Windbichler et al. 2011; Bian et al. 2013; Gantz et al. 2015; Hammond et al. 2016). Toward testing and wild release, large sets of molecular markers and genome sequences have been produced that can be used to study population structure and gene flow (Thomas et al. 2000; Black and Lanzaro 2001; Donnelly et al. 2001; Walton et al. 2001; Holt et al. 2002; Neafsey et al. 2015).

Genetic control can be broadly separated into germline transformation of mosquitoes, involving the germline manipulation of a genome and paratransgenesis-which works with transformation of obligate symbionts (Alphey et al. 2002). Paratransgenesis involves genetically modified organisms that can colonize vector species (Wilke and Marrelli 2015). Genetically modified symbiotic bacteria are reintroduced into the vector species where they express the genetic trait (Beard et al. 1993; Conte 1997; Favia et al. 2007; Coutinho-Abreu et al. 2010). These genetic traits may be a pathogenic effect in the host, interfering with reproduction, reducing vector competence (Bian et al. 2013) or the reproductive pathway (Yoshida et al. 2001; Chavshin et al. 2012; Bongio and Lampe 2015). Wolbachia have recently shown the ability to confer fitness costs on Anopheles vectors (Joshi et al. 2014) and inhibit Plasmodium infection (Jin et al. 2009; Kambris et al. 2010; Hughes et al. 2011). However, some studies have shown the opposite, where Plasmodium infections were enhanced in the presence of Wolbachia (Hughes et al. 2012). This finding necessitates a clearer understanding of underlying processes. Various other symbiotic bacteria species have been identified in anophelines and may be used for paratransgenesis, the choice of which is determined by the approach being used (Beard et al. 1993; Yoshida et al. 2001; GonzalezCeron et al. 2003; Lindh et al. 2005; Favia et al. 2007; Wilke and Marrelli 2015). An advantage of paratransgenesis over that of genetic transformation is that a transgeneic strain is required for every species or reproductively isolated strain in the latter, while the same paratransgenic system may be used for multiple species as long as the bacteria being used can survive and the system 
function in the vector species used (Sayler and Ripp 2000; Riehle and Jacobs-Lorena 2005; Riehle et al. 2007; Wilke and Marrelli 2015).

Suppression and replacement strategies: Outcomes of genetic control strategies include (1) both population suppression, where the number of vectors in a target population is reduced, and (2) population replacement, where a trait is spread in the natural vector population toward the reduction of vectorial capacity at some point in the vector life cycle (Alphey et al. 2002; Wilke and Marrelli 2012). The "release of insects with dominant lethality" (RIDL) system uses a dominant lethal gene with a female-specific promoter (Heinrich and Scott 2000; Thomas et al. 2000; Atkinson et al. 2007). When genetically modified, males mate with wild females, sexspecific lethality results in inviable female progeny. Several genes and lethal mechanisms may be used with this system (Fortini et al. 1992; Alphey 2002). Population-replacement strategies have resulted in several anopheline species being genetically modified toward the disruption of Plasmodium transmission. Anopheles stephensi was transformed to express a peptide that blocked the majority of oocyte development (Ito et al. 2002). Other studies that have shown the ability of germline transformation to reduce or inhibit malaria transmission include the expression of venom phospholipase (Zieler et al. 2001; Moreira et al. 2002), single-chain antibodies (Isaacs et al. 2011) and other antimalaria genes (Meredith et al. 2011).

Self-limiting and self-sustaining strategies: Self-limiting as well as self-sustaining strategies may be used (Alphey et al. 2002). A strategy that incorporates a strong fitness penalty will result in the rapid reduction of the target population by natural selection. Sterile insect technique (SIT) (Alphey 2002) is a highly effective, areawide method where periodic mass releases of irradiated and sterile males are required to maintain the selection pressure. Sterile-male methods incorporate the release of sterile males, which, because of infertile mating, results in population suppression (Helinski et al. 2008). Genetic sexing mechanisms that are self-sustained and stable offer a major benefit more than traditional SIT techniques that rely on ra- diation-based sterilization (Heinrich and Scott 2000; Thomas et al. 2000; Alphey 2002). In general, population replacement strategies are self-sustaining, whereas population suppression strategies are self-limiting (Alphey et al. 2002; Jasinskiene et al. 2007; Wilke and Marrelli 2012). Self-sustaining paratransgenic systems such as Wolbachia invade and are maintained in the population once initially established in the target (Alphey et al. 2002; Wilke and Marrelli 2012). Genetic transforming self-sustaining strategies usually consist of two components-a genetic refractory mechanism that enable either population suppression or refractoriness to disease transmission, as well as a gene-drive system (Sinkins and Gould 2006) that disseminates the transgene cargo into the population toward the disruption of disease transmission (Zieler et al. 2001; Ito et al. 2002; Moreira et al. 2002; Isaacs et al. 2011; Meredith et al. 2011). There are several gene-drive systems that include the use of selfish genetic elements like transposons (Burt 2003; Chen et al. 2007; Sethuraman et al. 2007), meiotic drive genes (Lyttle 1991), and homing endonuclease genes (HEGs) (Burt 2003; Deredec et al. 2008).

Transposable elements are able to move within a genome and increase their number (Scott et al. 2002). The spread of the P element in Drosophila melanogaster is an example of the spread of a transposon in a population (Kidwell 1992; Engels 1997). Although common in malaria vectors (Holt et al. 2002) and having been used in germline transformation (Catteruccia et al. 2000; Grossman et al. 2001; Perera et al. 2002), there have not been any studies showing their use as a gene-drive system in Anopheles vectors (Sinkins and Gould 2006).

Meiotic drive, usually in males, occurs when a heterozygous locus segregates at a greaterthan-expected frequency (Lyttle 1991; Sinkins and Gould 2006) through various mechanisms.

HEGs are selfish genetic elements naturally found in microbes (Burt and Koufopanou 2004; Stoddard 2005). They encode an endonuclease that recognizes and cleaves specific DNA sequences of $\sim 20-30$ nucleotides that usually is present only once in the genome. This gene is inserted into the cleaved sequence. In a hetero- 
N.F. Lobo et al.

zygous genome, the chromosome without the endonuclease gets cleaved and the broken chromosome gets repaired using the homolog containing the HEG thereby propagating itself in the genome. In principle, an HEG with a transgene cargo is able to cleave a highly conserved target gene and should be capable of population invasion from a low starting frequency (Deredec et al. 2008) with germline incorporation of an HEG transgene. HEGs may be used in two ways (Burt and Koufopanou 2004; Deredec et al. 2008), that is, an HEG can be engineered to recognize a specific nuclear gene/sequence where, on insertion, it would knockout the gene. An HEG construct may be engineered to recognize and insert into a repeat sequence on the $\mathrm{X}$ chromosome, be linked to meiosis-specific control sequences, and inserted on the $\mathrm{Y}$ chromosome. The HEG bearing Y would propagate in the population biasing the sex ration toward males (Galizi et al. 2014).

Multiple genetic control strategies are presently being investigated and some have successfully been tested in the field with other field tests ongoing.

\section{Integrated Vector Management (IVM)}

IVM is a rational decision-making process for the optimal use of resources for vector control (WHO 2004, 2011; Beier et al. 2008). This encompassing approach to prevent disease transmission relies on evidence-based decision making and aims to maximize the efficiency, cost effectiveness, ecological soundness, and sustainability of a disease vector program based on all available tools. Central to IVM is an understanding of the vector, the disease transmission cycle, the environment, and how the intervention strategy reduces man-vector contact, vector survival, and the intensity of disease transmission. The acceptability and safety of the strategies, as well as flexibility of the program, is vital to its success. The global strategic framework for IVM and the WHO handbook (WHO 1982, 2004) establish broad principles and approaches to vector control. Distinguishing factors of IVM include advocacy, social mobilization and legislation, collaboration within and outside the health sector, an integrated approach, evidence-based decision-making, and capacity building (WHO 2004; Beier et al. 2008). Success stories and various efforts in Africa include those in South Sudan (Chanda et al. 2013), Uganda (Mutero et al. 2012), Zambia (Chanda et al. 2008), among other countries (Alimi et al. 2015; Smith Gueye et al. 2016). Although, at present, the full extent of IVM on malaria transmission is unknown, historical implementations of IVM-like strategies have shown significant effects against disease transmission across a wide range of transmission settings (Beier et al. 2008). Evidence suggests that IVM can complement present malaria intervention programs such as ITN use, by avoiding the dependence on single intervention methods (Killeen et al. 2000; McKenzie et al. 2002; Caldas de Castro et al. 2004; Beier et al. 2008; Mutero et al. 2012, 2015).

Following on from evidence-based IVM strategies, central to the development and success of any intervention be it a combination or a single tool, is the understanding of the local vector species with their bionomic characteristics. The manner in which vector populations respond to these interventions and insecticideassociated selection pressures is required to evaluate effectiveness. Control measures may be profoundly impacted by the development of physiological insecticide resistance (Ranson et al. 2011; Gatton et al. 2013; Strode et al. 2014) and behavioral resistance-the ability of a vector population to change its bionomic characteristics in response to an intervention (Taylor 1975; Reddy et al. 2011; Russell et al. 2011, 2013; Bayoh et al. 2014). Epidemiology and entomology studies as well as vector-control programs require a strategic understanding of key local vector characteristics, such as feeding preferences and insecticide resistance, while also distinguishing vectors and nonvectors within anopheline cryptic species complexes, beyond the level of morphology. The wrong associations of local vector species with behavioral traits impact interpretations of species distributions, insecticide resistance, host preference studies, trap efficacy, and even screening for malaria parasites (Stevenson et al. 2012; Lobo 
et al. 2015) —all of which influence the efficacy of an intervention.

\section{CONCLUDING REMARKS AND FUTURE PERSPECTIVES}

Present recommended vector-control strategies rely primarily on ITNs and IRS and have shown significant impact on malaria transmission. However, these alone may not be able to eliminate malaria and point to the requirement for additional tools, some of which are outlined in this review. Although, none of these tools present a "magic bullet," their combination with other strategies may enhance local vector control strategies toward the elimination of malaria. The greatest opportunity for impact on elimination/eradication is the better understanding of susceptible vector bionomic traits that may be used for the implementation, development, and use of effective vector control tools. The development and validation of novel vector control tools (such as ATSBs and genetic modification), as well as new insecticides, are required to fill in gaps in protection and provide additional weapons in residual transmission settings where our current tools are inadequate. Combinations of interventions that target different aspects of a vectors life cycle would be more efficacious and could enable the reduction of residual transmission. Other technologies_-such as the use of satellite imagery-in combination with specific interventions can cater strategies to geographic requirements resulting in more efficacious interventions toward elimination.

The effectiveness of vector interventions toward elimination is dependent on local transmission dynamics that include nonvector factors such as access to health care, access to personal protective devices, and intervention distribution, human behavior, parasite species population dynamics, and drug resistance, among others. It is vital that a program aimed at geographic elimination or eradication incorporates both long-term feasibility and comprehensive primary stakeholder engagement (national, programmatic implementation, and research entities). Understanding and maximizing how various entities function in the inter- vention and elimination sphere and using entomological intelligence to design policies will allow for a larger effect on transmission. A systems approach should collates and analyze existing data characterizing malaria transmission dynamics while also identifying data gaps. Vital data should include entomological endpoints such as vector bionomics, epidemiological incidence and prevalence, human components that contribute to transmission such as migratory and travel patterns, and an evaluation of all stakeholder malaria-control efforts to include implementation and surveillance. This will allow the evaluation of vector intervention strategies in place, with a focus on their optimization while also examining the gaps in protection based on entomological bionomic data. Molecular analysis of Anopheles specimens will allow for a temporal characterization and association of bionomics with specific species-enabling the direct association of intervention efficacy with Anopheles species. Insecticide resistance tests will enable an indication of insecticide efficacy at the sites based on local interventions in place. Epidemiological interventions, such as mass drug administration, and other parasitesrelated activity should also be evaluated. Risk factors associated with human behaviors that affect transmission as well as local knowledge and practices must be examined. This systems analysis with associated filling of data gaps will enable the characterization of residual transmission: the optimization of present strategies as well as outlining possible tools that will fill gaps based on local transmission dynamics. As countries strive for malaria elimination, they must adopt proactive versus reactive strategies that will delay the onset of insecticide and/or behavioral resistance. Improved and sustained access to appropriate vector-control tools and strategies will be essential for the elimination and eradication of malaria.

\section{REFERENCES}

Achee N, Masuoka P, Smith P, Martin N, Chareonviryiphap T, Polsomboon S, Hendarto J, Grieco J. 2012a. Identifying the effective concentration for spatial repellency of the dengue vector Aedes aegypti. Parasit Vectors 5: 300 
N.F. Lobo et al.

Achee NL, Bangs MJ, Farlow R, Killeen GF, Lindsay S, Logan JG, Moore SJ, Rowland M, Sweeney K, Torr SJ, et al. 2012b. Spatial repellents: From discovery and development to evidence-based validation. Malaria J 11: 164.

Alimi TO, Fuller DO, Quinones ML, Xue RD, Herrera SV, Arevalo-Herrera M, Ulrich JN, Qualls WA, Beier JC. 2015. Prospects and recommendations for risk mapping to improve strategies for effective malaria vector control interventions in Latin America. Malaria J 14: 519.

Allan SA. 2011. Susceptibility of adult mosquitoes to insecticides in aqueous sucrose baits. J Vector Ecol 36: 59-67.

Alphey L. 2002. Re-engineering the sterile insect technique. Insect Biochem Mol Biol 32: 1243-1247.

Alphey L, Beard CB, Billingsley P, Coetzee M, Crisanti A, Curtis C, Eggleston P, Godfray C, Hemingway J, JacobsLorena M, et al. 2002. Malaria control with genetically manipulated insect vectors. Science 298: 119-121.

Atkinson MP, Su Z, Alphey N, Alphey LS, Coleman PG Wein LM. 2007. Analyzing the control of mosquitoborne diseases by a dominant lethal genetic system. Proc Natl Acad Sci 104: 9540-9545.

Bayoh MN, Mathias DK, Odiere MR, Mutuku FM, Kamau L, Gimnig JE, Vulule JM, Hawley WA, Hamel MJ, Walker ED. 2010. Anopheles gambiae: Historical population decline associated with regional distribution of insecticidetreated bed nets in western Nyanza Province, Kenya. $\mathrm{Ma}$ laria J 9: 62.

Bayoh MN, Walker ED, Kosgei J, Ombok M, Olang GB, Githeko AK, Killeen GF, Otieno P, Desai M, Lobo NF, et al. 2014. Persistently high estimates of late night, indoor exposure to malaria vectors despite high coverage of insecticide treated nets. Parasit Vectors 7: 380.

Beard CB, O’Neill SL, Tesh RB, Richards FF, Aksoy S. 1993. Modification of arthropod vector competence via symbiotic bacteria. Parasitol Today 9: 179-183.

Beier JC, Keating J, Githure JI, Macdonald MB, Impoinvil DE, Novak RJ. 2008. Integrated vector management for malaria control. Malaria J 7: S4.

Beier JC, Muller GC, Gu W, Arheart KL, Schlein Y. 2012. Attractive toxic sugar bait (ATSB) methods decimate populations of Anopheles malaria vectors in arid environments regardless of the local availability of favoured sug ar-source blossoms. Malaria J 11: 31.

Bian G, Joshi D, Dong Y, Lu P, Zhou G, Pan X, Xu Y, Dimopoulos G, Xi Z. 2013. Wolbachia invades Anopheles stephensi populations and induces refractoriness to Plasmodium infection. Science 340: 748-751.

Black WCt, Lanzaro GC. 2001. Distribution of genetic variation among chromosomal forms of Anopheles gambiae s.s.: Introgressive hybridization, adaptive inversions, or recent reproductive isolation? Insect Mol Biol 10: 3-7.

Bongio NJ, Lampe DJ. 2015. Inhibition of Plasmodium berghei development in mosquitoes by effector proteins secreted from Asaia sp. bacteria using a novel native secretion signal. PLoS ONE 10: e0143541.

Bouma M, Rowland M. 1995. Failure of passive zooprophylaxis: Cattle ownership in Pakistan is associated with a higher prevalence of malaria. Trans R Soc Trop Med Hyg 89: $351-353$.

Bourguinat C, Pion SD, Kamgno J, Gardon J, Duke BO, Boussinesq M, Prichard RK. 2007. Genetic selection of low fertile Onchocerca volvulus by ivermectin treatment. PLoS Negl Trop Dis 1: e72.

Briegel H. 2003. Physiological bases of mosquito ecology. J Vector Ecol 28: 1-11.

Bugoro H. 2011. "The bionomics of Anopheles farauti and prospects for malaria elimination in the Solomon Islands." PhD thesis, National Yang-Ming University, Institute of Clinical Medicine, Taipei, Taiwan.

Bugoro H, Iro'ofa C, Mackenzie DO, Apairamo A, Hevalao W, Corcoran S, Bobogare A, Beebe NW, Russell TL, Chen CC, et al. 2011. Changes in vector species composition and current vector biology and behaviour will favour malaria elimination in Santa Isabel Province, Solomon Islands. Malaria J 10: 287.

Burnham G, Mebrahtu T. 2004. The delivery of ivermectin (Mectizan). Trop Med Int Health 9: A26-44.

Burt A. 2003. Site-specific selfish genes as tools for the control and genetic engineering of natural populations. Proc Biol Sci 270: 921-928.

Burt A, Koufopanou V. 2004. Homing endonuclease genes: The rise and fall and rise again of a selfish element. Curr Opin Genet Dev 14: 609-615.

Caldas de Castro M, Yamagata Y, Mtasiwa D, Tanner M, Utzinger J, Keiser J, Singer BH. 2004. Integrated urban malaria control: A case study in Dar es Salaam, Tanzania. Am J Trop Med Hyg 71: 103-117.

Catteruccia F, Nolan T, Loukeris TG, Blass C, Savakis C, Kafatos FC, Crisanti A. 2000. Stable germline transformation of the malaria mosquito Anopheles stephensi. $\mathrm{Na}$ ture 405: 959-962.

Chaccour C, Killeen GF. 2016. Mind the gap: Residual malaria transmission, veterinary endectocides and livestock as targets for malaria vector control. Malaria J 15: 24.

Chanda E, Masaninga F, Coleman M, Sikaala C, Katebe C, Macdonald M, Baboo KS, Govere J, Manga L. 2008. Integrated vector management: The Zambian experience. Malaria J 7: 164

Chanda E, Govere JM, Macdonald MB, Lako RL, Haque U, Baba SP, Mnzava A. 2013. Integrated vector management: A critical strategy for combating vector-borne diseases in South Sudan. Malaria J 12: 369.

Chavshin AR, Oshaghi MA, Vatandoost H, Pourmand MR, Raeisi A, Enayati AA, Mardani N, Ghoorchian S. 2012. Identification of bacterial microflora in the midgut of the larvae and adult of wild caught Anopheles stephensi: A step toward finding suitable paratransgenesis candidates. Acta Trop 121: 129-134.

Chen CH, Huang H, Ward CM, Su JT, Schaeffer LV, Guo M, Hay BA. 2007. A synthetic maternal-effect selfish genetic element drives population replacement in Drosophila. Science 316: 597-600.

Clyde DF. 1967. Malaria in Tanzania. Oxford University Press, London.

Conte JE Jr. 1997. A novel approach to preventing insectborne diseases. N Engl J Med 337: 785-786.

Cook SM, Khan ZR, Pickett JA. 2007. The use of push-pull strategies in integrated pest management. Annu Rev Entomol 52: 375-400.

Corbel V, Akogbeto M, Damien GB, Djenontin A, Chandre F, Rogier C, Moiroux N, Chabi J, Banganna B, Padonou GG, et al. 2012. Combination of malaria vector control 
interventions in pyrethroid resistance area in Benin: A cluster randomised controlled trial. Lancet Infect Dis 12: $617-626$.

Coutinho-Abreu IV, Zhu KY, Ramalho-Ortigao M. 2010. Transgenesis and paratransgenesis to control insectborne diseases: Current status and future challenges. Parasitol Int 59: 1-8.

Curtis CF. 1968. Possible use of translocations to fix desirable genes in insect pest populations. Nature 218: 368 369.

D’Acremont V, Lengeler C, Genton B. 2010. Reduction in the proportion of fevers associated with Plasmodium falciparum parasitaemia in Africa: A systematic review. $\mathrm{Ma}$ laria J 9: 240.

De Lara Capurro M, Coleman J, Beerntsen BT, Myles KM, Olson KE, Rocha E, Krettli AU, James AA. 2000. Virusexpressed, recombinant single-chain antibody blocks sporozoite infection of salivary glands in Plasmodium gallinaceum-infected Aedes aegypti. Am J Trop Med Hyg 62: $427-433$.

delas Llagas L, Hernandez L, Samaniego J. 1996. Insecticidal zooprophylaxis. ENHR Executive Brief (Philippines) 2: $3-7$.

Deredec A, Burt A, Godfray HC. 2008. The population genetics of using homing endonuclease genes in vector and pest management. Genetics 179: 2013-2026.

Donnelly MJ, Licht MC, Lehmann T. 2001. Evidence for recent population expansion in the evolutionary history of the malaria vectors Anopheles arabiensis and Anopheles gambiae. Mol Biol Evol 18: 1353-1364.

Donnelly B, Berrang-Ford L, Ross NA, Michel P. 2015. A systematic, realist review of zooprophylaxis for malaria control. Malaria J 14: 313

Duke BO, Zea-Flores G, Castro J, Cupp EW, Munoz B. 1990. Effects of multiple monthly doses of ivermectin on adult Onchocerca volvulus. Am J Trop Med Hyg 43: 657-664.

Elliott R. 1972. The influence of vector behavior on malaria transmission. Am J Trop Med Hyg 21: 755-763.

Engels WR. 1997. Invasions of P elements. Genetics 145: 11 15.

Favia G, Ricci I, Damiani C, Raddadi N, Crotti E, Marzorati M, Rizzi A, Urso R, Brusetti L, Borin S, et al. 2007. Bacteria of the genus Asaia stably associate with Anopheles stephensi, an Asian malarial mosquito vector. Proc Natl Acad Sci 104: 9047-9051.

Fillinger U, Lindsay SW. 2011. Larval source management for malaria control in Africa: Myths and reality. Malaria J 10: 353 .

Fillinger U, Knols BG, Becker N. 2003. Efficacy and efficiency of new Bacillus thuringiensis var israelensis and Bacillus sphaericus formulations against Afrotropical anophelines in Western Kenya. Trop Med Int Health 8: 37-47.

Fillinger U, Sonye G, Killeen GF, Knols BG, Becker N. 2004. The practical importance of permanent and semipermanent habitats for controlling aquatic stages of Anopheles gambiae sensu lato mosquitoes: Operational observations from a rural town in Western Kenya. Trop Med Int Health 9: $1274-1289$.

Fillinger U, Ndenga B, Githeko A, Lindsay SW. 2009. Integrated malaria vector control with microbial larvicides and insecticide-treated nets in Western Kenya: A controlled trial. Bull World Health Organ 87: 655-665.

Fortini ME, Simon MA, Rubin GM. 1992. Signalling by the sevenless protein tyrosine kinase is mimicked by Ras 1 activation. Nature 355: 559-561.

Foster WA. 1995. Mosquito sugar feeding and reproductive energetics. Annu Rev Entomol 40: 443-474.

Foster WA, Takken W. 2004. Nectar-related vs. human-related volatiles: Behavioural response and choice by female and male Anopheles gambiae (Diptera: Culicidae) between emergence and first feeding. Bull Entomol Res 94: $145-157$.

Foy BD, Kobylinski KC, da Silva IM, Rasgon JL, Sylla M. 2011. Endectocides for malaria control. Trends Parasitol 27: $423-428$.

Fullman N, Burstein R, Lim SS, Medlin C, Gakidou E. 2013. Nets, spray or both? The effectiveness of insecticide-treated nets and indoor residual spraying in reducing malaria morbidity and child mortality in sub-Saharan Africa. Malaria J 12: 62.

Galizi R, Doyle LA, Menichelli M, Bernardini F, Deredec A, Burt A, Stoddard BL, Windbichler N, Crisanti A. 2014. A synthetic sex ratio distortion system for the control of the human malaria mosquito. Nat Commun 5: 3977.

Gantz VM, Jasinskiene N, Tatarenkova O, Fazekas A, Macias VM, Bier E, James AA. 2015. Highly efficient Cas9-mediated gene drive for population modification of the malaria vector mosquito Anopheles stephensi. Proc Natl Acad Sci 112: E6736-E6743.

Garrett-Jones C, Shidrawi GR. 1969. Malaria vectorial capacity of a population of Anopheles gambiae: An exercise in epidemiological entomology. Bull World Health Organ 40: $531-545$.

Gary RE Jr, Foster WA. 2006. Diel timing and frequency of sugar feeding in the mosquito Anopheles gambiae, depending on sex, gonotrophic state and resource availability. Med Vet Entomol 20: 308-316.

Gatton ML, Chitnis N, Churcher T, Donnelly MJ, Ghani AC, Godfray HC, Gould F, Hastings I, Marshall J, Ranson H, et al. 2013. The importance of mosquito behavioural adaptations to malaria control in Africa. Evolution 67: $1218-1230$.

Gimnig JE, Otieno P, Were V, Marwanga D, Abong'o D, Wiegand R, Williamson J, Wolkon A, Zhou Y, Bayoh $\mathrm{MN}$, et al. 2016. The effect of indoor residual spraying on the prevalence of malaria parasite infection, clinical malaria and anemia in an area of perennial transmission and moderate coverage of insecticide treated nets in Western Kenya. PLoS ONE 11: e0145282.

Glunt KD, Abilio AP, Bassat Q, Bulo H, Gilbert AE, Huijben S, Manaca MN, Macete E, Alonso P, Paaijmans KP. 2015. Long-lasting insecticidal nets no longer effectively kill the highly resistant Anopheles funestus of southern Mozambique. Malaria J 14: 298.

Goldman AS, Guisinger VH, Aikins M, Amarillo ML, Belizario VY, Garshong B, Gyapong J, Kabali C, Kamal HA Kanjilal S, et al. 2007. National mass drug administration costs for lymphatic filariasis elimination. PLoS Negl Trop Dis 1: e67.

Gonzalez-Ceron L, Santillan F, Rodriguez MH, Mendez D, Hernandez-Avila JE. 2003. Bacteria in midguts of field- 


\section{N.F. Lobo et al.}

collected Anopheles albimanus block Plasmodium vivax sporogonic development. J Med Entomol 40: 371-374.

Goodyer LI, Croft AM, Frances SP, Hill N, Moore SJ, Onyango SP, Debboun M. 2010. Expert review of the evidence base for arthropod bite avoidance. J Travel Med 17: 182-192.

Grieco JP, Achee NL, Andre RG, Roberts DR. 2000. A comparison study of house entering and exiting behavior of Anopheles vestitipennis (Diptera: Culicidae) using experimental huts sprayed with DDT or deltamethrin in the southern district of Toledo, Belize, C.A. J Vector Ecol 25: $62-73$.

Grieco JP, Vogtsberger RC, Achee NL, Vanzie E, Andre RG, Roberts DR, Rejmankova E. 2005. Evaluation of habitat management strategies for the reduction of malaria vectors in northern Belize. J Vector Ecol 30: 235-243.

Grieco JP, Achee NL, Chareonviriyaphap T, Suwonkerd W, Chauhan K, Sardelis MR, Roberts DR. 2007. A new classification system for the actions of IRS chemicals traditionally used for malaria control. PLoS ONE 2: e716.

Grimstad PR, DeFoliart GR. 1974. Nectar sources of Wisconsin mosquitoes. J Med Entomol 11: 331-341.

Grossman GL, Rafferty CS, Clayton JR, Stevens TK, Mukabayire O, Benedict MQ. 2001. Germline transformation of the malaria vector, Anopheles gambiae, with the piggyBac transposable element. Insect Mol Biol 10: 597-604.

Gu W, Muller G, Schlein Y, Novak RJ, Beier JC. 2011. Natural plant sugar sources of Anopheles mosquitoes strongly impact malaria transmission potential. PLoS ONE 6: e15996.

Guzzo CA, Furtek CI, Porras AG, Chen C, Tipping R, Clineschmidt CM, Sciberras DG, Hsieh JY, Lasseter KC 2002. Safety, tolerability, and pharmacokinetics of escalating high doses of ivermectin in healthy adult subjects. J Clin Pharmacol 42: 1122-1133.

Hamel MJ, Otieno P, Bayoh N, Kariuki S, Were V, Marwanga D, Laserson KF, Williamson J, Slutsker L, Gimnig J. 2011. The combination of indoor residual spraying and insecticide-treated nets provides added protection against malaria compared with insecticide-treated nets alone. Am J Trop Med Hyg 85: 1080-1086.

Hammond A, Galizi R, Kyrou K, Simoni A, Siniscalchi C, Katsanos D, Gribble M, Baker D, Marois E, Russell S, et al. 2016. A CRISPR-Cas9 gene drive system targeting female reproduction in the malaria mosquito vector Anopheles gambiae. Nat Biotechnol 34: 78-83.

Hawley WA, Phillips-Howard PA, ter Kuile FO, Terlouw DJ, Vulule JM, Ombok M, Nahlen BL, Gimnig JE, Kariuki SK, Kolczak MS, et al. 2003. Community-wide effects of permethrin-treated bed nets on child mortality and malaria morbidity in Western Kenya. Am J Trop Med Hyg 68: 121-127.

Heinrich JC, Scott MJ. 2000. A repressible female-specific lethal genetic system for making transgenic insect strains suitable for a sterile-release program. Proc Natl Acad Sci 97: 8229-8232.

Helinski ME, Hassan MM, El-Motasim WM, Malcolm CA, Knols BG, El-Sayed B. 2008. Towards a sterile insect technique field release of Anopheles arabiensis mosquitoes in Sudan: Irradiation, transportation, and field cage experimentation. Malaria J 7: 65.
Hewitt S, Kamal M, Muhammad N, Rowland M. 1994. An entomological investigation of the likely impact of cattle ownership on malaria in an Afghan refugee camp in the North West Frontier Province of Pakistan. Med Vet Entomol 8: 160-164.

Hill N, Lenglet A, Arnez AM, Carneiro I. 2007. Plant based insect repellent and insecticide treated bed nets to protect against malaria in areas of early evening biting vectors: Double blind randomised placebo controlled clinical trial in the Bolivian Amazon. BMJ 335: 1023.

Hill N, Zhou HN, Wang P, Guo X, Carneiro I, Moore SJ. 2014. A household randomized, controlled trial of the efficacy of $0.03 \%$ transfluthrin coils alone and in combination with long-lasting insecticidal nets on the incidence of Plasmodium falciparum and Plasmodium vivax malaria in western Yunnan Province, China. Malaria J 13: 208.

Holstein M. 1954. Biology of Anopheles gambiae: Research in French West Africa. Monograph series. World Health Organization, Geneva.

Holt RA, Subramanian GM, Halpern A, Sutton GG, Charlab R, Nusskern DR, Wincker P, Clark AG, Ribeiro JM, Wides $\mathrm{R}$, et al. 2002. The genome sequence of the malaria mosquito Anopheles gambiae. Science 298: 129-149.

Hopkins M. 1940. Afforestation as a method of drying up swamps. East African Med J 17: 189-194.

Howard SC, Omumbo J, Nevill C, Some ES, Donnelly CA, Snow RW. 2000. Evidence for a mass community effect of insecticide-treated bednets on the incidence of malaria on the Kenyan coast. Trans R Soc Trop Med Hyg 94: 357 360.

Hughes GL, Koga R, Xue P, Fukatsu T, Rasgon JL. 2011. Wolbachia infections are virulent and inhibit the human malaria parasite Plasmodium falciparum in Anopheles gambiae. PLoS Pathog 7: e1002043.

Hughes GL, Vega-Rodriguez J, Xue P, Rasgon JL. 2012. Wolbachia strain wAlbB enhances infection by the rodent malaria parasite Plasmodium berghei in Anopheles gambiae mosquitoes. Appl Environ Microbiol 78: 1491-1495.

Isaacs AT, Li F, Jasinskiene N, Chen X, Nirmala X, Marinotti O, Vinetz JM, James AA. 2011. Engineered resistance to Plasmodium falciparum development in transgenic Anopheles stephensi. PLoS Pathog 7: e1002017.

Ito J, Ghosh A, Moreira LA, Wimmer EA, Jacobs-Lorena M. 2002. Transgenic anopheline mosquitoes impaired in transmission of a malaria parasite. Nature 417: 452-455.

James AA, Beerntsen BT, Capurro Mde L, Coates CJ, Coleman J, Jasinskiene N, Krettli AU. 1999. Controlling malaria transmission with genetically engineered, Plasmodium-resistant mosquitoes: Milestones in a model system. Parassitologia 41: 461-471.

Jasinskiene N, Coleman J, Ashikyan A, Salampessy M, Marinotti O, James AA. 2007. Genetic control of malaria parasite transmission: Threshold levels for infection in an avian model system. Am J Trop Med Hyg 76: 10721078 .

Jin C, Ren X, Rasgon JL. 2009. The virulent Wolbachia strain wMelPop efficiently establishes somatic infections in the malaria vector Anopheles gambiae. Appl Environ Microbiol 75: 3373-3376. 
Joshi D, McFadden MJ, Bevins D, Zhang F, Xi Z. 2014 Wolbachia strain wAlbB confers both fitness costs and benefit on Anopheles stephensi. Parasit Vectors 7: 336.

Kambris Z, Blagborough AM, Pinto SB, Blagrove MS, Godfray HC, Sinden RE, Sinkins SP. 2010. Wolbachia stimulates immune gene expression and inhibits Plasmodium development in Anopheles gambiae. PLoS Pathog 6: e1001143.

Kawada H, Maekawa Y, Tsuda Y, Takagi M. 2004a. Trial of spatial repellency of metofluthrin-impregnated paper strip against Anopheles and Culex in shelters without walls in Lombok, Indonesia. J Am Mosq Control Assoc 20: $434-437$.

Kawada H, Maekawa Y, Tsuda Y, Takagi M. 2004b. Laboratory and field evaluation of spatial repellency with metofluthrin-impregnated paper strip against mosquitoes in Lombok Island, Indonesia. J Am Mosq Control Assoc 20: 292-298.

Kidwell MG. 1992. Horizontal transfer of P elements and other short inverted repeat transposons. Genetica 86: $275-286$.

Killeen GF. 2014. Characterizing, controlling and eliminating residual malaria transmission. Malaria J 13: 330.

Killeen GF, McKenzie FE, Foy BD, Schieffelin C, Billingsley PF, Beier JC. 2000. The potential impact of integrated malaria transmission control on entomologic inoculation rate in highly endemic areas. Am J Trop Med Hyg 62: $545-551$.

Killeen GF, Seyoum A, Sikaala C, Zomboko AS, Gimnig JE, Govella NJ, White MT. 2013. Eliminating malaria vectors. Parasit Vectors 6: 172.

Killeen GF, Seyoum A, Gimnig JE, Stevenson JC, Drakeley CJ, Chitnis N. 2014. Made-to-measure malaria vector control strategies: Rational design based on insecticide properties and coverage of blood resources for mosquitoes. Malaria J 13: 146.

Kitau J, Pates H, Rwegoshora TR, Rwegoshora D, Matowo J, Kweka EJ, Mosha FW, McKenzie K, Magesa SM. 2010. The effect of mosquito magnet liberty plus trap on the human mosquito biting rate under semi-field conditions. J Am Mosq Control Assoc 26: 287-294.

Kiware SS, Chitnis N, Devine GJ, Moore SJ, Majambere S, Killeen GF. 2012. Biologically meaningful coverage indicators for eliminating malaria transmission. Biol Lett 8: 874-877.

Kleinschmidt I, Schwabe C, Shiva M, Segura JL, Sima V, Mabunda SJ, Coleman M. 2009. Combining indoor residual spraying and insecticide-treated net interventions. Am J Trop Med Hyg 81: 519-524.

Lea AO. 1965. Sugar-baited insecticide residues against mosquitoes. Mosq News 25: 65-66.

Lengeler C. 2000. Insecticide-treated bednets and curtains for preventing malaria. Cochrane Database Syst Rev 2000: Cd000363.

Lengeler C. 2004. Insecticide-treated bed nets and curtains for preventing malaria. Cochrane Database Syst Rev 2004: Cd000363.

Lindh JM, Terenius O, Faye I. 2005. 16S rRNA gene-based identification of midgut bacteria from field-caught Anopheles gambiae sensu lato and $A$. funestus mosquitoes reveals new species related to known insect symbionts. Appl Environ Microbiol 71: 7217-7223.

Lindsay SW, Gibson ME. 1988. Bednets revisited-Old idea, new angle. Parasitol Today 4: 270-272.

Lobo NF, Clayton JR, Fraser MJ, Kafatos FC, Collins FH. 2006. High efficiency germ-line transformation of mosquitoes. Nat Protoc 1: 1312-1317.

Lobo NF, Laurent BS, Sikaala CH, Hamainza B, Chanda J, Chinula D, Krishnankutty SM, Mueller JD, Deason NA, Hoang QT, et al. 2015. Unexpected diversity of Anopheles species in Eastern Zambia: Implications for evaluating vector behavior and interventions using molecular tools. Sci Rep 5: 17952.

Lucas JR, Shono Y, Iwasaki T, Ishiwatari T, Spero N, Benzon G. 2007. U.S. laboratory and field trials of metofluthrin (SumiOne) emanators for reducing mosquito biting outdoors. J Am Mosq Control Assoc 23: 47-54.

Lyttle TW. 1991. Segregation distorters. Annu Rev Genet 25: 511-557.

Mabaso ML, Sharp B, Lengeler C. 2004. Historical review of malarial control in southern African with emphasis on the use of indoor residual house-spraying. Trop Med Int Health 9: 846-856.

Maia MF, Onyango SP, Thele M, Simfukwe ET, Turner EL, Moore SJ. 2013. Do topical repellents divert mosquitoes within a community? Health equity implications of topical repellents as a mosquito bite prevention tool. PLoS ONE 8: e84875.

malERA Consultative Group on Vector Control. 2011. A research agenda for malaria eradication: Vector control. PLoS Med 8: e1000401.

McKenzie FE, Baird JK, Beier JC, Lal AA, Bossert WH. 2002. A biologic basis for integrated malaria control. Am J Trop Med Hyg 67: 571-577.

Menger DJ, Otieno B, de Rijk M, Mukabana WR, van Loon JJ, Takken W. 2014. A push-pull system to reduce house entry of malaria mosquitoes. Malaria J 13: 119.

Meredith JM, Basu S, Nimmo DD, Larget-Thiery I, Warr EL, Underhill A, McArthur CC, Carter V, Hurd H, Bourgouin $\mathrm{C}$, et al. 2011. Site-specific integration and expression of an anti-malarial gene in transgenic Anopheles gambiae significantly reduces Plasmodium infections. PLoS ONE 6: e14587.

Mnzava AP, Knox TB, Temu EA, Trett A, Fornadel C, Hemingway J, Renshaw M. 2015. Implementation of the global plan for insecticide resistance management in malaria vectors: Progress, challenges and the way forward. Malaria J 14: 173.

Moreira LA, Ito J, Ghosh A, Devenport M, Zieler H, Abraham EG, Crisanti A, Nolan T, Catteruccia F, Jacobs-Lorena M. 2002. Bee venom phospholipase inhibits malaria parasite development in transgenic mosquitoes. J Biol Chem 277: 40839-40843.

Muirhead-Thomson RC. 1945. Studies on the breeding places and control of Anopheles gambiae and A. gambiae var. melas in coastal districts of Sierra Leone. Bull Entomol Res 36: 185-252.

Muirhead-Thomson RC (ed.). 1951. Behaviour in relation to malaria transmission and control in the tropics. Edward Arnold \& Co. London. 


\section{N.F. Lobo et al.}

Mulamba C, Riveron JM, Ibrahim SS, Irving H, Barnes KG Mukwaya LG, Birungi J, Wondji CS. 2014. Widespread pyrethroid and DDT resistance in the major malaria vector Anopheles funestus in East Africa is driven by metabolic resistance mechanisms. PLoS ONE 9: e110058.

Muller G, Schlein Y. 2005. Plant tissues: The frugal diet of mosquitoes in adverse conditions. Med Vet Entomol 19: $413-422$.

Muller G, Schlein Y. 2006. Sugar questing mosquitoes in arid areas gather on scarce blossoms that can be used for control. Int J Parasitol 36: 1077-1080.

Muller GC, Kravchenko VD, Schlein Y. 2008. Decline of Anopheles sergentii and Aedes caspius populations following presentation of attractive toxic (spinosad) sugar bait stations in an oasis. J Am Mosq Control Assoc 24: 147149.

Muller GC, Beier JC, Traore SF, Toure MB, Traore MM, Bah S, Doumbia S, Schlein Y. 2010a. Field experiments of Anopheles gambiae attraction to local fruits/seedpods and flowering plants in Mali to optimize strategies for malaria vector control in Africa using attractive toxic sugar bait methods. Malaria J 9: 262.

Muller GC, Junnila A, Schlein Y. 2010b. Effective control of adult Culex pipiens by spraying an attractive toxic sugar bait solution in the vegetation near larval habitats. J Med Entomol 47: 63-66.

Muller GC, Beier JC, Traore SF, Toure MB, Traore MM, Bah S, Doumbia S, Schlein Y. 2010c. Successful field trial of attractive toxic sugar bait (ATSB) plant-spraying methods against malaria vectors in the Anopheles gambiae complex in Mali, West Africa. Malaria J 9: 210.

Mutero CM, Schlodder D, Kabatereine N, Kramer R. 2012. Integrated vector management for malaria control in Uganda: Knowledge, perceptions and policy development. Malaria J 11: 21.

Mutero CM, Mbogo C, Mwangangi J, Imbahale S, Kibe L, Orindi B, Girma M, Njui A, Lwande W, Affognon H, et al. 2015. An assessment of participatory integrated vector management for malaria control in Kenya. Environ Health Perspect 123: 1145-1151.

Nasci RS, McLaughlin RE, Focks D, Billodeaux JS. 1990. Effect of topically treating cattle with permethrin on blood feeding of Psorophora columbiae (Diptera: Culicidae) in a southwestern Louisiana rice-pasture ecosystem. J Med Entomol 27: 1031-1034.

Nayar JK, Sauerman DM Jr. 1971. The effects of diet on lifespan, fecundity and flight potential of Aedes taeniorhynchus adults. J Med Entomol 8: 506-513.

Nayar JK, Sauerman DM Jr. 1975a. The effects of nutrition on survival and fecundity in Florida mosquitoes. Part 1: Utilization of sugar for survival. J Med Entomol 12: $92-$ 98.

Nayar JK, Sauerman DM Jr. 1975b. The effects of nutrition on survival and fecundity in Florida mosquitoes. Part 3: Utilization of blood and sugar for fecundity. J Med Entomol 12: 220-225.

Neafsey DE, Waterhouse RM, Abai MR, Aganezov SS, Alekseyev MA, Allen JE, Amon J, Arca B, Arensburger P, Artemov G, et al. 2015. Mosquito genomics. Highly evolvable malaria vectors: The genomes of 16 Anopheles mosquitoes. Science 347: 1258522.
N'Guessan R, Corbel V, Akogbeto M, Rowland M. 2007. Reduced efficacy of insecticide-treated nets and indoor residual spraying for malaria control in pyrethroid resistance area, Benin. Emerg Infect Dis 13: 199-206.

Nyarango PM, Gebremeskel T, Mebrahtu G, Mufunda J, Abdulmumini U, Ogbamariam A, Kosia A, Gebremichael A, Gunawardena D, Ghebrat Y, et al. 2006. A steep decline of malaria morbidity and mortality trends in Eritrea between 2000 and 2004: The effect of combination of control methods. Malaria J 5: 33.

Ogoma SB, Ngonyani H, Simfukwe ET, Mseka A, Moore J, Killeen GF. 2012. Spatial repellency of transfluthrin-treated hessian strips against laboratory-reared Anopheles arabiensis mosquitoes in a semi-field tunnel cage. Parasit Vectors 5: 54 .

Ogoma SB, Ngonyani H, Simfukwe ET, Mseka A, Moore J, Maia MF, Moore SJ, Lorenz LM. 2014. The mode of action of spatial repellents and their impact on vectorial capacity of Anopheles gambiae sensu stricto. PLoS ONE 9: el10433.

O'Meara WP, Mangeni JN, Steketee R, Greenwood B. 2010. Changes in the burden of malaria in sub-Saharan Africa. Lancet Infect Dis 10: 545-555.

Pates HV, Line JD, Keto AJ, Miller JE. 2002. Personal protection against mosquitoes in Dar es Salaam, Tanzania, by using a kerosene oil lamp to vaporize transfluthrin. Med Vet Entomol 16: 277-284.

Paz-Soldan VA, Plasai V, Morrison AC, Rios-Lopez EJ, Guedez-Gonzales S, Grieco JP, Mundal K, Chareonviriyaphap T, Achee NL. 2011. Initial assessment of the acceptability of a push-pull Aedes aegypti control strategy in Iquitos, Peru and Kanchanaburi, Thailand. Am J Trop Med Hyg 84: $208-217$.

Perera OP, Harrell IR, Handler AM. 2002. Germ-line transformation of the South American malaria vector, Anopheles albimanus, with a piggyBac/EGFP transposon vector is routine and highly efficient. Insect Mol Biol 11: 291297.

Pinder M, Jawara M, Jarju LB, Salami K, Jeffries D, Adiamoh M, Bojang K, Correa S, Kandeh B, Kaur H, et al. 2015. Efficacy of indoor residual spraying with dichlorodiphenyltrichloroethane against malaria in Gambian communities with high usage of long-lasting insecticidal mosquito nets: A cluster-randomised controlled trial. Lancet 385: $1436-1446$.

Protopopoff N, Wright A, West PA, Tigererwa R, Mosha FW, Kisinza W, Kleinschmidt I, Rowland M. 2015. Combination of insecticide treated nets and indoor residual spraying in Northern Tanzania provides additional reduction in vector population density and malaria transmission rates compared to insecticide treated nets alone: A randomised control trial. PLoS ONE 10: e0142671.

Pyke B, Rice M, Sabine B, Zalucki M. 1987. The push-pull strategy-Behavioural control of Heliothis. Austr Cotton Grow 8: 7-9.

Quinones ML, Norris DE, Conn JE, Moreno M, Burkot TR, Bugoro H, Keven JB, Cooper R, Yan G, Rosas A, et al. 2015. Insecticide resistance in areas under investigation by the international centers of excellence for malaria research: A challenge for malaria control and elimination. Am J Trop Med Hyg 93: 69-78. 
Ranson H, N'Guessan R, Lines J, Moiroux N, Nkuni Z, Corbel V. 2011. Pyrethroid resistance in African anopheline mosquitoes: What are the implications for malaria control? Trends Parasitol 27: 91-98.

Reddy GV, Guerrero A. 2010. New pheromones and insect control strategies. Vitam Horm 83: 493-519.

Reddy MR, Overgaard HJ, Abaga S, Reddy VP, Caccone A, Kiszewski AE, Slotman MA. 2011. Outdoor host seeking behaviour of Anopheles gambiae mosquitoes following initiation of malaria vector control on Bioko Island, Equatorial Guinea. Malaria J 10: 184.

Reisen WK, Meyer RP, Milby MM. 1986. Patterns of fructose feeding by Culex tarsalis (Diptera: Culicidae). J Med Entomol 23: $366-373$.

Riehle MA, Jacobs-Lorena M. 2005. Using bacteria to express and display anti-parasite molecules in mosquitoes: Current and future strategies. Insect Biochem Mol Biol 35: 699-707.

Riehle MA, Moreira CK, Lampe D, Lauzon C, Jacobs-Lorena M. 2007. Using bacteria to express and display anti-Plasmodium molecules in the mosquito midgut. Int J Parasitol 37: 595-603.

Robert LL, Perich MJ, Schlein Y, Jacobson RL, Wirtz RA, Lawyer PG, Githure JI. 1997. Phlebotomine sand fly control using bait-fed adults to carry the larvicide Bacillus sphaericus to the larval habitat. J Am Mosq Control Assoc 13: $140-144$.

Russell TL, Govella NJ, Azizi S, Drakeley CJ, Kachur SP, Killeen GF. 2011. Increased proportions of outdoor feeding among residual malaria vector populations following increased use of insecticide-treated nets in rural Tanzania. Malaria J 10: 80.

Russell TL, Beebe NW, Cooper RD, Lobo NF, Burkot TR. 2013. Successful malaria elimination strategies require interventions that target changing vector behaviours. Malaria J 12: 56

Saul A. 2003. Zooprophylaxis or zoopotentiation: The outcome of introducing animals on vector transmission is highly dependent on the mosquito mortality while searching. Malaria J 2: 32.

Sayler GS, Ripp S. 2000. Field applications of genetically engineered microorganisms for bioremediation processes. Curr Opin Biotechnol 11: 286-289.

Schlein Y, Muller GC. 2008. An approach to mosquito control: Using the dominant attraction of flowering Tamarix jordanis trees against Culex pipiens. J Med Entomol 45: 384-390.

Schlein Y, Pener H. 1990. Bait-fed adult Culex pipiens carry the larvicide Bacillus sphaericus to the larval habitat. Med Vet Entomol 4: 283-288.

Schultz GW. 1989. Animal influence on man-biting rates at a malarious site in Palawan, Philippines. Southeast Asian J Trop Med Public Health 20: 49-53.

Scott TW, Takken W, Knols BG, Boete C. 2002. The ecology of genetically modified mosquitoes. Science 298: 117119.

Sethuraman N, Fraser MJ Jr, Eggleston P, O'Brochta DA. 2007. Post-integration stability of piggyBac in Aedes aegypti. Insect Biochem Mol Biol 37: 941-951.

Shaukat AM, Breman JG, McKenzie FE. 2010. Using the entomological inoculation rate to assess the impact of vector control on malaria parasite transmission and elimination. Malaria J 9: 122.

Shousha AT. 1948. Species-eradication: The eradication of Anopheles gambiae from Upper Egypt, 1942-1945. Bull World Health Organ 1: 309-352.

Sinkins SP, Gould F. 2006. Gene drive systems for insect disease vectors. Nat Rev Genet 7: 427-435.

Smith DL, McKenzie FE, Snow RW, Hay SI. 2007. Revisiting the basic reproductive number for malaria and its implications for malaria control. PLoS Biol 5: e42.

Smith Gueye C, Newby G, Gosling RD, Whittaker MA, Chandramohan D, Slutsker L, Tanner M. 2016. Strategies and approaches to vector control in nine malaria-eliminating countries: A cross-case study analysis. Malaria J 15: 2 .

Soper FL, Wilson DB. 1943. Anopheles gambiae in Brazil. The Rockefeller Foundation, New York.

Stevenson J, St Laurent B, Lobo NF, Cooke MK, Kahindi SC, Oriango RM, Harbach RE, Cox J, Drakeley C. 2012. Novel vectors of malaria parasites in the western highlands of Kenya. Emerg Infect Dis 18: 1547-1549.

Stoddard BL. 2005. Homing endonuclease structure and function. Q Rev Biophys 38: 49-95.

Stone CM, Jackson BT, Foster WA. 2012. Effects of bed net use, female size, and plant abundance on the first meal choice (blood vs sugar) of the malaria mosquito Anopheles gambiae. Malaria J 11: 3.

Strode C, Donegan S, Garner P, Enayati AA, Hemingway J. 2014. The impact of pyrethroid resistance on the efficacy of insecticide-treated bed nets against African anopheline mosquitoes: Systematic review and meta-analysis. PLoS Med 11: e1001619.

Strycharz JP, Yoon KS, Clark JM. 2008. A new ivermectin formulation topically kills permethrin-resistant human head lice (Anoplura: Pediculidae). J Med Entomol 45: $75-$ 81.

Suwannachote N, Grieco JP, Achee NL, Suwonkerd W, Wongtong S, Chareonviriyaphap T. 2009. Effects of environmental conditions on the movement patterns of Aedes aegypti (Diptera: Culicidae) into and out of experimental huts in Thailand. J Vector Ecol 34: 267-275.

Syafruddin D, Bangs MJ, Sidik D, Elyazar I, Asih PB, Chan K, Nurleila S, Nixon C, Hendarto J, Wahid I, et al. 2014 Impact of a spatial repellent on malaria incidence in two villages in Sumba, Indonesia. Am J Trop Med Hyg 91: 1079-1087.

Taylor B. 1975. Changes in the feeding behaviour of a malaria vector, Anopheles farauti Lav., following the use of DDT as a residual spray in houses in the British Solomon Islands Protectorate. Trans R Entomol Soc London 127: 277-292.

Temu EA, Maxwell C, Munyekenye G, Howard AF, Munga S, Avicor SW, Poupardin R, Jones JJ, Allan R, Kleinschmidt I, et al. 2012. Pyrethroid resistance in Anopheles gambiae, in Bomi County, Liberia, compromises malaria vector control. PLoS ONE 7: e44986.

Thomas DD, Donnelly CA, Wood RJ, Alphey LS. 2000. Insect population control using a dominant, repressible, lethal genetic system. Science 287: 2474-2476.

Toe KH, Jones CM, N’Fale S, Ismail HM, Dabire RK, Ranson H. 2014. Increased pyrethroid resistance in malaria vec- 
N.F. Lobo et al.

tors and decreased bed net effectiveness, Burkina Faso. Emerg Infect Dis 20: 1691-1696.

Tusting LS, Thwing J, Sinclair D, Fillinger U, Gimnig J, Bonner KE, Bottomley C, Lindsay SW. 2013. Mosquito larval source management for controlling malaria. Cochrane Database Syst Rev 8: CD008923.

Wagman JM, Grieco JP, Bautista K, Polanco J, Briceno I, King R, Achee NL. 2015. The field evaluation of a push-pull system to control malaria vectors in northern Belize, Central America. Malaria J 14: 184.

Walshe DP, Garner P, Abdel-Hameed Adeel AA, Pyke GH, Burkot T. 2013. Larvivorous fish for preventing malaria transmission. Cochrane Database Syst Rev 12: CD008090.

Walton C, Handley JM, Collins FH, Baimai V, Harbach RE, Deesin V, Butlin RK. 2001. Genetic population structure and introgression in Anopheles dirus mosquitoes in South-east Asia. Mol Ecol 10: 569-580.

Watson M. 1911. The prevention of malaria in the Federated Malay States. Liverpool School of Tropical Medicine, Liverpool, UK.

Watson M (ed.). 1953. African highway: The battle for health in central Africa. John Murray, London.

West PA, Protopopoff N, Wright A, Kivaju Z, Tigererwa R, Mosha FW, Kisinza W, Rowland M, Kleinschmidt I. 2014. Indoor residual spraying in combination with insecticide-treated nets compared to insecticide-treated nets alone for protection against malaria: A cluster randomised trial in Tanzania. PLoS Med 11: e1001630.

West PA, Protopopoff N, Wright A, Kivaju Z, Tigererwa R, Mosha FW, Kisinza W, Rowland M, Kleinschmidt I. 2015. Enhanced protection against malaria by indoor residual spraying in addition to insecticide treated nets: Is it dependent on transmission intensity or net usage? PLoS ONE 10: $\mathrm{e} 0115661$.

WHO. 1982. Manual on environmental management for mosquito control with special emphasis on malaria vectors. WHO offset publication No. 66. World Health Organization, Geneva.

WHO. 1993. A global strategy for malaria control. World Health Organization, Geneva.

WHO. 2004. Global strategic framework for integrated vector management. World Health Organization, Geneva.

WHO. 2011. Position statement on integrated vector management to control malaria and lymphatic filariasis. Wkly Epidemiol Rec 86: 121-127.

WHO. 2012a. Global plan for insecticide resistance management in malaria vectors. World Health Organization, Geneva.
WHO. 2012b. Interim position statement: The role of larviciding for malaria control in sub-Saharan Africa. World Health Organization, Geneva.

WHO. 2013. Larval source management. A supplementary measure for malaria vector control. An operational manual. World Health Organization, Geneva.

WHO. 2014. Guidance note: Control of residual malaria parasite transmission. World Health Organization, Geneva.

WHO. 2015a. World malaria report 2015. World Health Organization, Geneva.

WHO. 2015b. Information note on the risks associated with the scale back of vector control in areas where transmission has been reduced. World Health Organization, Geneva.

Wilke AB, Marrelli MT. 2012. Genetic control of mosquitoes: Population suppression strategies. Rev Inst Med Trop Sao Paulo 54: 287-292.

Wilke AB, Marrelli MT. 2015. Paratransgenesis: A promising new strategy for mosquito vector control. Parasit Vectors 8: 342 .

Wilson ML. 1993. Avermectins in arthropod vector management—Prospects and pitfalls. Parasitol Today 9: 83-87.

Windbichler N, Menichelli M, Papathanos PA, Thyme SB, Li H, Ulge UY, Hovde BT, Baker D, Monnat RJ Jr, Burt A, et al. 2011. A synthetic homing endonuclease-based gene drive system in the human malaria mosquito. Nature 473: 212-215.

Xue RD, Barnard DR. 2003. Boric acid bait kills adult mosquitoes (Diptera: Culicidae). J Econ Entomol 96: 15591562.

Xue RD, Kline DL, Ali A, Barnard DR. 2006. Application of boric acid baits to plant foliage for adult mosquito control. J Am Mosq Control Assoc 22: 497-500.

Xue RD, Ali A, Kline DL, Barnard DR. 2008. Field evaluation of boric acid- and fipronil-based bait stations against adult mosquitoes. J Am Mosq Control Assoc 24: 415-418.

Yoshida S, Ioka D, Matsuoka H, Endo H, Ishii A. 2001. Bacteria expressing single-chain immunotoxin inhibit malaria parasite development in mosquitoes. Mol Biochem Parasitol 113: 89-96.

Zieler H, Keister DB, Dvorak JA, Ribeiro JM. 2001. A snake venom phospholipase $\mathrm{A}_{2}$ blocks malaria parasite development in the mosquito midgut by inhibiting ookinete association with the midgut surface. J Exp Biol 204: 4157-4167. 


\section{$\&_{\mathrm{CSH}}^{\infty} \&$ Cold Spring Harbor

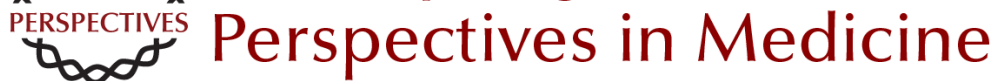

\section{Modern Vector Control}

Neil F. Lobo, Nicole L. Achee, John Greico and Frank H. Collins

Cold Spring Harb Perspect Med 2018; doi: 10.1101/cshperspect.a025643 originally published online May 15, 2017

\section{Subject Collection Malaria: Biology in the Era of Eradication}

Modern Vector Control

Neil F. Lobo, Nicole L. Achee, John Greico, et al.

Anopheline Reproductive Biology: Impacts on Vectorial Capacity and Potential Avenues for

Malaria Control Sara N. Mitchell and Flaminia Catteruccia

Current and Future Prospects for Preventing Malaria Transmission via the Use of Insecticides Hilary Ranson

Molecular Signaling Involved in Entry and Exit of Malaria Parasites from Host Erythrocytes Shailja Singh and Chetan E. Chitnis

Vaccines to Accelerate Malaria Elimination and Eventual Eradication Julie Healer, Alan F. Cowman, David C. Kaslow, et al.

Immune Responses in Malaria Carole A. Long and Fidel Zavala

Antimalarial Drug Resistance: A Threat to Malaria Elimination Didier Menard and Arjen Dondorp

Malaria during Pregnancy Michal Fried and Patrick E. Duffy
Malaria Pathogenesis Danny A. Milner, Jr.

Determinants of Malaria Transmission at the Population Level Teun Bousema and Chris Drakeley

\section{Host Cell Tropism and Adaptation of Blood-Stage Malaria Parasites: Challenges for Malaria \\ Elimination Caeul Lim, Selasi Dankwa, Aditya S. Paul, et al.}

Malaria Transmission and Prospects for Malaria Eradication: The Role of the Environment Marcia C. Castro

The Biology of Plasmodium vivax John H. Adams and Ivo Mueller

Malaria Genomics in the Era of Eradication Daniel E. Neafsey and Sarah K. Volkman

Malaria Epigenetics Alfred Cortés and Kirk W. Deitsch

Malaria Parasite Liver Infection and Exoerythrocytic Biology Ashley M. Vaughan and Stefan H.I. Kappe

For additional articles in this collection, see http://perspectivesinmedicine.cshlp.org/cgi/collection/ 